\title{
Postoperative Haematocrit and Outcome in Critically III Surgical Patients
}

\section{Hematócrito Pós-operatório e Resultados numa População de Doentes Críticos Cirúrgicos}

Ana Martins LOPES ${ }^{1}$, Diana SILVA ${ }^{1}$, Gabriela SOUSA ${ }^{1}$, Joana SILVA ${ }^{1}$, Alice SANTOS ${ }^{1}$, Fernando José ABELHA $\triangle 1,2$ Acta Med Port 2017 Jul-Aug;30(7-8):555-560 - https://doi.org/10.20344/amp.7930

\begin{abstract}
Introduction: Haematocrit has been studied as an outcome predictor. The aim of this study was to evaluate the correlation between low haematocrit at surgical intensive care unit admission and high disease scoring system score and early outcomes.

Material and Methods: This retrospective study included 4398 patients admitted to the surgical intensive care unit between January 2006 and July 2013. Acute physiology and chronic health evaluation and simplified acute physiology score II values were calculated and all variables entered as parameters were evaluated independently. Patients were classified as haematocrit if they had a haematocrit $<30 \%$ at surgical intensive care unit admission. The correlation between admission haematocrit and outcome was evaluated by univariate analysis and linear regression.
\end{abstract}

Results: A total of 1126 (25.6\%) patients had haematocrit. These patients had higher rates of major cardiac events (4\% vs $1.9 \%$, $p<0.001)$, acute renal failure $(11.5 \%$ vs $4.7 \%, p<0.001)$, and mortality during surgical intensive care unit stay $(3 \%$ vs $0.8 \%, p<0.001)$ and hospital stay $(12 \%$ vs $5.9 \%, p<0.001)$.

Discussion: A haematocrit level $<30 \%$ at surgical intensive care unit admission was frequent and appears to be a predictor for poorer outcome in critical surgical patients.

Conclusion: Patients with haematocrit had longer surgical intensive care unit and hospital stay lengths, more postoperative complications, and higher surgical intensive care unit and hospital mortality rates.

Keywords: Anemia; Critical Care; Hematocrit; Outcome Assessment; Postoperative Complications; Postoperative Period

\section{RESUMO}

Introdução: O valor do hematócrito tem sido estudado como preditor de resultados. O objetivo deste estudo foi avaliar a relação entre um hematócrito baixo na admissão a uma unidade de cuidados intensivos cirúrgica e os sistemas de gravidade bem como o seu impacto nos resultados tendo em conta as complicações e a mortalidade.

Material e Métodos: Estudo retrospetivo incluindo 4398 doentes internados numa Unidade de Cuidados Intensivos Cirúrgica entre janeiro de 2006 e julho de 2013. Foram calculados os scores de gravidade acute physiology and chronic health evaluation II e o simplified acute physiology score II, e todas as variáveis inseridas como parâmetros foram avaliadas separadamente. Os doentes com um hematócrito à admissão na Unidade de Cuidados Intensivos Cirúrgica inferior a 30 foram classificados como doentes com hematócrito baixo. A relação entre o hematócrito na admissão e as complicações e o resultado foram avaliados com uma análise univariada e uma regressão linear.

Resultados: Os doentes com classificados como doentes com hematócrito baixo foram 1126 (25,6\%). Os doentes classificados como doentes com hematócrito baixo tiveram mais frequentemente eventos cardíacos major ( $\%$ vs $1,9 \%, p<0,001)$, lesão renal aguda $(11,5 \%$ vs $4,7 \%, p<0,001)$ e maiores taxas de mortalidade quer na Unidade de Cuidados Intensivos Cirúrgica $(3 \%$ vs $0,8 \%, p<0,001)$ quer no internamento hospitalar $(12 \%$ vs $5,9 \%, p<0,001)$.

Discussão: Um valor de hematócrito $<30 \%$ na admissão na Unidade de Cuidados Intensivos foi frequente e parece ser um preditor de piores resultados em doentes cirúrgicos críticos.

Conclusão: Os doentes com hematócrito baixo tiveram mais tempo de internamento na Unidade de Cuidados Intensivos Cirúrgica e no hospital, tiveram mais complicações pós-operatórias e taxas de mortalidade na Unidade de Cuidados Intensivos Cirúrgica e no hospital mais elevadas.

Palavras-chave: Anemia; Avaliação de Resultados; Complicações Pós-Operatórias; Cuidados Críticos; Hematócrito; Período PósOperatório

\section{INTRODUCTION}

Several factors may impair organic homeostasis under surgical stress and influence the outcomes of high-risk patients. ${ }^{1}$ Anaemia is a common multifactorial condition in intensive care units (ICU). ${ }^{2,3}$ The deleterious effects of anaemia include an increased risk of cardiac-related morbidity and mortality, ${ }^{4}$ in part due to a decreased oxygencarrying capacity. Since critical illness increases metabolic demands, the consequences of anaemia could be more significant in this population. ${ }^{4,5}$ Even mild anaemia $(29 \%<$

$\mathrm{HTC} \leq 39 \%$ in men and $29 \%<\mathrm{HTC} \leq 36 \%$ in women) has been reported as an independent factor that increases 30 day mortality rates. ${ }^{6,7}$ On the other hand, the transfusion of only one unit of red blood cells significantly increases 30 day mortality rates. ${ }^{8}$

Haematocrit (HTC) has been studied as a transfusion trigger and outcome predictor. $^{9}$ It is known that values $<30 \%$ can be tolerated by many patients; however, it is unclear whether this is true in critically ill patients.

1. Department of Anaesthesiology. Hospital de São João. Porto. Portugal.

2. Department of Surgery. Anaesthesiology and Perioperative Medicine Unit. Faculdade de Medicina. Universidade do Porto. Porto. Portugal.

$\triangle$ Autor correspondente: Fernando José Abelha. fernando.abelha@gmail.com

Recebido: 12 de junho de 2016 - Aceite: 03 de maio de 2017 | Copyright $\odot$ Ordem dos Médicos 2017 
Despite the demonstrated correlation between lower HTC levels and poorer outcomes, the specific impact of anaemia on ICU patient morbidity and mortality rates has yet to be defined. ${ }^{10,11}$ As such, the optimal anaemia management standards remain controversial. In surgical patients, HTC levels during 24 hour SICU admission depend on preoperative status and perioperative management.

Complications following major surgery are a leading cause of morbidity and mortality, ${ }^{7}$ while the general surgical population has become older and sicker. ${ }^{12}$

In this set of sicker patients, the initial assessment is essential for risk stratification and management adjustment. Moreover, it is crucial to establish criteria to classify a patient's risk when the use of a surgical procedure is proposed. ${ }^{13}$

Many risk models have been designed to characterize disease severity and predict outcome and organ dysfunction degree in the postoperative setting. The acute physiology and chronic health evaluation (APACHE) II and simplified acute physiology score (SAPS) II are two of the most commonly used tools. The APACHE II score varies from 0 to 71 points and is based upon age, previous health status, and 12 routine physiologic measurements. ${ }^{14}$ It is closely correlated with the risk of hospital death and enables the stratification of acutely ill patients. SAPS II values are calculated using 12 physiological variables and consider pre-admission health status and age. ${ }^{15}$ APACHE II and SAPS II scores perform similarly in predicting the outcomes of patients in the SICU. ${ }^{16}$

Major cardiac events (MCE) are relatively uncommon but associated with longer hospital stays, higher treatment costs, and higher mortality and morbidity rates. ${ }^{17}$ The frequency of these episodes varies considerably depending on the characteristics of the studied population, but an incidence of $2 \%-4 \%$ might be an accurate estimate. ${ }^{18-20}$ These events might be difficult to predict since they frequently cause no early symptoms ${ }^{21}$ or electrocardiography changes. Therefore, an accurate preoperative assessment is essential for guiding an individualized patient approach, establishing prophylactic treatment, optimizing perioperative management, and enabling the early detection of possible cardiac complications.

A better understanding of outcome predictors in critical surgical patients will allow an individualized perioperative approach, the establishment of prophylactic measures, and the early detection of complications. Few studies have focused on postoperative HTC, and to our knowledge, only one study focused on a critical surgical population, although it was restricted to vascular patients. ${ }^{22}$

Therefore, this study aimed to evaluate the correlation between LHTC at surgical intensive care unit (SICU) admission, high disease scoring system scores, and the impact of HTC on early outcomes according to patient complications and hospital mortality rates.

\section{MATERIAL AND METHODS}

Upon receiving approval from the institutional research ethics committee, we conducted this retrospective cohort study at the post-anaesthesia care unit of a tertiary care centre. This unit has a five-bed SICU where patients are closely monitored and treated. SICU admissions were determined according to surgical risk, previous heath status, and the occurrence of adverse events. All patients underwent non-cardiac surgery between 1 January 2006 and 19 July 2013, and those who were admitted to the SICU were eligible for inclusion. Patients were excluded if they were $<18$ years of age, non-surgical patients, re-admitted for the same medical reason during the study period, or in the SICU for $<12$ hours.

Patients with an HTC value $<30 \%$ were considered to have low HTC (LHTC). At SICU admission, patient demographic and perioperative data such as age, sex, and surgery type (elective or urgent) were collected. An individual cardiac risk profile, namely the Revised Cardiac Risk Index (RCRI) developed by Lee et al, was scored. The $\mathrm{RCRI}$ consists of the following variables: high-risk surgery, history of congestive heart failure, history of ischemic heart disease, history of cerebrovascular disease, insulin therapy for diabetes, and preoperative serum creatinine $>2.0 \mathrm{mg} /$ dL. ${ }^{18}$

APACHE II and SAPS II values were both calculated as originally described [4,5]. The variables included the following: hemodynamic factors; complete blood counts; blood biochemistry values including HTC, leucocyte count, serum sodium, bicarbonate, bilirubin, urea, creatinine, and potassium levels; systolic and mean arterial blood pressure; body temperature; heart and respiratory rate; arterial $\mathrm{pH}$, $\mathrm{PaO}_{2}$, and $\mathrm{PaCO}_{2}$; and Glasgow Coma Scale score. The failure of at least one organ, defined according to the APACHE II score, was recorded as organ insufficiency. The need for mechanical ventilation and the fraction of inspired oxygen at admission were also documented.

Postoperative complications, specifically MCE, acute renal failure (ARF), or death, were recorded. We defined MCE as the occurrence of acute myocardial infarction (according to the European Society of Cardiology/American College of Cardiology criteria), ${ }^{23}$ pulmonary oedema, ventricular fibrillation, primary cardiac arrest, or complete heart block. Creatinine $>2 \mathrm{mg} / \mathrm{dL}$, associated with a urinary debit $<500 \mathrm{~mL} / \mathrm{d}$, was identified as ARF. Length of stay (LOS) in the SICU was also recorded.

A descriptive analysis was performed to summarize the collected data. Data are presented as median and percentile interval (P25 - P75) for continuous variables after confirmation on the Kolmogorov-Smirnov test that they did not follow a normal distribution.

Variables were compared on univariate analysis. The chi-square or Fischer's exact test was used to compare categorical variables, while the Mann-Whitney $U$ test was used to compare continuous variables. Linear regression was used to determine the impact of HTC on high disease scoring system score and SICU LOS. Additionally, logistic regression was performed to assess the covariate effects of HTC on mortality, LOS, and complications with the 
calculation of odds ratio $(O R)$ and its $95 \%$ confidence interval $(\mathrm{Cl})$. Because of multiple comparisons effects, the variables were considered significant at values of $p \leq 0.001$.

\section{RESULTS}

During the study period, 4398 patients met the inclusion criteria. The following 163 patients were excluded: 53 had a LOS < 12 hour, 42 were re-admitted, 38 were $<18$ years of age, and 30 were non-surgical patients. Demographics and perioperative data are presented in Table 1. Among the included patients, 1126 (25.6\%) had LHTC.

The median patient age was 65 years old; $61 \%$ were male. The majority of the patients were admitted in the context of an elective surgery (70\%), while 1341 (30.5\%) were on mechanical ventilation. Sixty patients $(1.4 \%)$ died in the unit and $327(7.4 \%)$ died during the hospital stay. MCE occurred in 107 (2.4\%) patients, while 285 (6.5\%) developed ARF in the SICU.

The median age of the patients with LHTC was 66 years, and $58.2 \%$ of them were male (Table 1). Patients with LHTC were more likely than patients with an $\mathrm{HTC}>30 \%$ to have undergone non-elective surgery ( $21 \%$ vs $10.2 \%, p<0.001)$, be on mechanical ventilation at admission $(39.5 \%$ vs $27.4 \%$, $p<0.001)$, and have organ insufficiency $(20.2 \%$ vs $13.9 \%$,

Table 1 - Univariate analysis of patients demographics

\begin{tabular}{|c|c|c|c|}
\hline Variables & $\begin{array}{c}\text { HTC }<30 \\
n=1126\end{array}$ & $\begin{array}{c}H T C \geq 30 \\
n=3272\end{array}$ & $p$ value \\
\hline \multicolumn{4}{|l|}{ Gender, n (\%) } \\
\hline Male & $655(58.2)$ & $2026(61.9)$ & $0.026^{a}$ \\
\hline Female & $471(41.8)$ & $1246(38.1)$ & \\
\hline Age, median (IQR) & $66.0(53.0-75.0)$ & $65.0(54.0-74.0)$ & $0.382^{\mathrm{b}}$ \\
\hline \multicolumn{4}{|l|}{ Type of admission, $n(\%)$} \\
\hline Elective surgery & $889(79.0)$ & $2938(89.8)$ & $<0.001^{a}$ \\
\hline Non-elective surgery & $237(21.0)$ & $334(10.2)$ & \\
\hline Mechanical ventilation on admission, $\mathrm{n}(\%)$ & $445(39.5)$ & $896(27.4)$ & $<0.001^{\mathrm{a}}$ \\
\hline \multicolumn{4}{|l|}{ Glasgow scale, n (\%) } \\
\hline$>9$ & $1108(98.4)$ & $3236(98.9)$ & $0.209^{a}$ \\
\hline$\leq 9$ & $18(1.6)$ & $36(1.1)$ & \\
\hline Organ insufficiency ${ }^{c}, \mathrm{n}(\%)$ & $228(20.2)$ & $454(13.9)$ & $<0.001^{a}$ \\
\hline Body temperature, median (IQR) & $35.6(34.3-36.0)$ & $35.8(34.7-36.0)$ & $<0.001^{\mathrm{b}}$ \\
\hline Systolic pressure, median (IQR) & $117.0(96.0-137.0)$ & $123.0(105.0-144.0)$ & $<0.001^{\mathrm{b}}$ \\
\hline Mean arterial pressure, median (IQR) & $79.0(65.0-93.0)$ & $86.0(73.0-97.0)$ & $<0.001^{b}$ \\
\hline Heart rate, median (IQR) & $88.0(72.0-102.0)$ & $82.0(68.0-94.0)$ & $<0.001^{b}$ \\
\hline Respiratory rate, median (IQR) & $14.0(12.0-16.0)$ & $14.0(12.0-16.0)$ & $0.021^{b}$ \\
\hline Serum urea, median (IQR) & $30.0(20.0-45.0)$ & $30.0(20.0-40.0)$ & $0.623^{b}$ \\
\hline Serum creatinine, median (IQR) & $8.6(6.6-12.0)$ & $8.0(6.5-10.5)$ & $<0.001^{b}$ \\
\hline Total bilirubin, median (IQR) & $4.0(1.0-8.0)$ & $4.0(1.0-7.0)$ & $0.088^{b}$ \\
\hline $\mathrm{FiO}_{2}$, median (IQR) & $0.40(0.40-0.40)$ & $0.40(0.35-0.40)$ & $<0.001^{\mathrm{b}}$ \\
\hline $\mathrm{PaO}_{2}$, median (IQR) & 100. $(99.0-120.0)$ & $100.0(100.0$ - 108.0) & $0.012^{b}$ \\
\hline $\mathrm{PaCO}_{2}$, median (IQR) & $39.9(35.0-45.0)$ & $39.4(35.0-45.0)$ & $0.466^{b}$ \\
\hline Serum bicarbonate, median (IQR) & $22.0(21.0-24.0)$ & $22.0(21.0-24.0)$ & $0.182^{b}$ \\
\hline $\mathrm{pH}$, median (IQR) & $7.40(7.35-7.40)$ & $7.40(7.35-7.40)$ & $0.002^{b}$ \\
\hline Serum potassium, median (IQR) & $3.70(3.30-4.13)$ & $3.80(3.50-4.10)$ & $0.025^{b}$ \\
\hline Serum sodium, median (IQR) & $140.0(137.0-143.0)$ & $140.0(138.0-142.0)$ & $0.865^{b}$ \\
\hline Leucocytes count, median (IQR) & $10.8(7.4-14.1)$ & $11.0(8.3-14.0)$ & $0.005^{b}$ \\
\hline MCE, n (\%) & $45(4.0)$ & $62(1.9)$ & $<0.001^{a}$ \\
\hline ARF, n (\%) & $130(11.5)$ & $155(4.7)$ & $<0.001^{a}$ \\
\hline SICU LOS (hours), median (IQR) & $32.0(18.0-65.0)$ & $20.0(16.0-36.0)$ & $<0.001^{b}$ \\
\hline Mortality in SICU, n (\%) & $34(3.0)$ & $26(0.8)$ & $<0.001^{\mathrm{a}}$ \\
\hline Mortality in hospital, n (\%) & $135(12.0)$ & $192(5.9)$ & $<0.001^{a}$ \\
\hline
\end{tabular}

Htc: haematocrit; $\mathrm{FiO}_{2}$ : fraction of inspired oxygen; $\mathrm{PaO}_{2}$ : partial pressure arterial oxygen; $\mathrm{PaCO}_{2}$ : partial pressure arterial carbon dioxide; MCE: major cardiac events; $\mathrm{ARF}$ : acute renal failure; SICU: surgical intensive care unit; LOS: length of stay; N: number; IQR: interquartile range (P25-P75).

${ }^{a}$ chi-square test; ${ }^{b}$ Mann-Whitney test; ${ }^{\circ}$ organ insufficiency defined by APACHE II 
$p<0.001)$. A higher proportion of patients with LHTC had MCE $(4 \%$ vs $1.9 \%, p<0.001)$ or ARF $(11.5 \%$ vs $4.7 \%, p<$ $0.001)$, and they were more likely to stay longer in the SICU (32 vs 20 hours, $p<0.001$ ). Likewise, LHTC patients had higher SICU mortality rates in the SICU (3\% vs 0.8\%, $p<$ $0.001)$ and in hospital $(12 \%$ vs $5.9 \%, p<0.001)$.

During 24-hour SICU admission, patients with LHTC had a lower mean body temperature $(p<0.001)$, arterial systolic pressure $(p<0.001)$, and mean arterial pressure $(p$ $<0.001)$ as well as a higher heart rate $(p<0.001)$, serum creatinine $(p<0.001)$, and $\mathrm{FiO}_{2}(p<0.001)$ than patients with $\mathrm{HTC}>30 \%$.

Table 2 presents data related to disease scoring system score and individual cardiac risk profile (namely RCRI) accordingly to HTC level. A higher proportion of patients with LHTC had a history of renal disease $(10.8 \%$ vs $4.9 \%, p<$ $0.001)$ and RCRI > 2 (10.8\% vs. $6.7 \%, p<0.001)$; however, a lower proportion had a history of cerebrovascular disease (9.9\% vs $13.7 \%, p<0.001)$. Regarding disease scores, LHTC patients had higher mean APACHE II (11 vs 8, $p<$ 0.001 ) and SAPS II scores (24.4 vs 17.8, $p<0.001)$.

On linear regression (Table 3 ), for each unit increase in HTC value, the APACHE II score decreases 0.25 (95\% Cl, -0.27 to $-0.22 ; p<0.001$ ) and SAPS II score decreases 0.39 (95\% Cl, -0.52 to $-0.26 ; p<0.001)$. In addition, the SICU LOS decreases by 1.38 hours $(95 \% \mathrm{Cl}$; -1.60 to -1.16 ; $p<$ $0.001)$ for each unit increase in HTC value.

Regarding the occurrence of postoperative complications (Table 4), an increase in HTC was considered a protective factor for MCE $(p<0.001$; OR, 0.93; 95\% Cl, $0.83-0.91)$ and for mortality in the SICU $(p<0.001$; OR, $0.87 ; 95 \% \mathrm{CI}$, $0.83-0.91)$ or hospital ( $p<0.001$; OR, $0.9 ; 95 \% \mathrm{Cl}, 0.90-$ 0.94).

\section{DISCUSSION}

To our knowledge, this is the first study of postoperative HTC and outcomes in selected non-cardiac critical surgical patients.

Surgical blood loss is an important determining factor of patients' postoperative HTC levels, but even without significant blood loss, they may have significant reductions in HTC that are not entirely explained by intraoperative blood loss or dilution. ${ }^{24,25}$ In critically ill patients, the body's erythropoietic response to anaemia is blunted as a consequence of diminished iron availability and the direct inhibitory effects of inflammatory cytokines. ${ }^{26}$

Several studies have assessed the correlation between lower preoperative HTC level and worse outcome in surgical patients. ${ }^{27,28}$ However, due to the high frailty of critically ill patients and the huge variability of the stress imposed by surgery or blood loss, we suppose that postoperative HTC in a selected population is more reliable than preoperative HTC for predicting patient outcomes.

In our study, patients with LHTC were more likely to have a longer SICU LOS or die in the SICU, which are similar to the results reported by Mudumbai et al. ${ }^{9}$ In that study, the authors stated that patients with an HTC $<30 \%$ during the 24-hour ICU admission were more likely to have a longer hospital LOS and to die within 1 year postdischarge. Moreover, they described the highest mortality

Table 2 - Univariate analysis for Revised Cardiac Risk Index and Severity of Disease Scoring Systems

\begin{tabular}{|c|c|c|c|}
\hline Variables & $\begin{array}{c}\text { HTC }<30 \\
n=1126\end{array}$ & $\begin{array}{c}\text { HTC } \geq 30 \\
n=3272\end{array}$ & $p$ value \\
\hline High-risk surgery, n (\%) & $605(53.7)$ & $1777(54.3)$ & $0.737^{\mathrm{a}}$ \\
\hline History of ischemic heart disease, $\mathrm{n}(\%)$ & $184(16.3)$ & $433(13.2)$ & $0.010^{\mathrm{a}}$ \\
\hline History of congestive heart disease, $\mathrm{n}(\%)$ & $206(18.3)$ & $485(14.8)$ & $0.006^{a}$ \\
\hline Preoperative insulin therapy, $\mathrm{n}(\%)$ & $62(5.5)$ & $153(4.7)$ & $0.265^{a}$ \\
\hline Preoperative serum creatinine $>2.0 \mathrm{mg} / \mathrm{dL}, \mathrm{n}(\%)$ & $122(10.8)$ & $159(4.9)$ & $<0.001^{\mathrm{a}}$ \\
\hline History of cerebrovascular disease, $\mathrm{n}(\%)$ & $112(9.9)$ & $447(13.7)$ & $<0.001^{\mathrm{a}}$ \\
\hline \multicolumn{4}{|l|}{ RCRI, n (\%) } \\
\hline$\leq 2$ & $1016(89.2)$ & $3054(93.3)$ & $<0.001^{\mathrm{c}}$ \\
\hline$>2$ & $110(10.8)$ & $218(6.7)$ & \\
\hline APACHE II, median (IQR) & $11.0(8.0-14.0)$ & $8.0(5.0-11.0)$ & $<0.001^{\mathrm{b}}$ \\
\hline SAPS II, median (IQR) & $24.4(17.8-31.1)$ & $17.8(12.0-24.4)$ & $<0.001^{\mathrm{b}}$ \\
\hline
\end{tabular}

HTC: haematocrit; RCRI: revised cardiac risk index; APACHE II: acute physiology and chronic health evaluation; SAPS II: simplified acute physiology score II; N: number; IQR: interquartile range (P25-P75).

${ }^{\text {a }}$ chi-square test; ${ }^{\mathrm{b}}$ Mann-Whitney test; ${ }^{\circ}$ Fisher's exact test

Table 3 - Linear regression model for HTC variation

\begin{tabular}{lcc}
\hline Variables & $\boldsymbol{\beta}$ & $\boldsymbol{p}$ value \\
\hline APACHE II, median (IQR) & -0.247 & $<\mathbf{0 . 0 0 1}$ \\
SAPS II, median (IQR) & -0.389 & $<\mathbf{0 . 0 0 1}$ \\
SICU LOS (hours), median (IQR) & -1.379 & $<\mathbf{0 . 0 0 1}$ \\
\hline
\end{tabular}

APACHE II: acute physiology and chronic health evaluation; SAPS II: simplified acute physiology score II; SICU: surgical intensive care unit; LOS: length of stay; IQR: interquartile range (P25-P75).
Table 4 - Logistic regression model for HTC variation

\begin{tabular}{lcc}
\hline Variables & OR $(\mathrm{Cl} \mathrm{95 \% )}$ & $\boldsymbol{p}$ value \\
\hline Mortality in SICU & $0.87(0.83-0.91)$ & $<0.001$ \\
Mortality in hospital & $0.90(0.90-0.94)$ & $<0.001$ \\
MCE & $0.93(0.83-0.91)$ & $<0.001$ \\
\hline
\end{tabular}

OR: odds ratio; Cl: confidence interval; SICU: surgical intensive care unit; MCE: major cardiac events 
rate in patients with an $\mathrm{HTC}$ level $<25 \%$ and reported that the benefits of red blood cell transfusions outweigh the risks in this group only. In our study on critical care patients, all patients had surgical stress in common as an ensuing reason to an impaired response to anaemia. Wu et $a^{29}$ also reported higher postoperative mortality rates within 30 days in patients with preoperative lower HTC.

In our study, LHTC patients more frequently had a preoperative serum creatinine level $>2.0 \mathrm{mg} / \mathrm{dL}$ and were more likely to develop ARF in the SICU. This correlation between anaemia and renal function is explained by the fact that both anaemia and renal disease are risk factors for ARF. ${ }^{30}$ Moreover, LHTC patients were more likely to have lower systolic and mean arterial pressures, which are also risk factors for ARF.

There are differences in compensatory responses to anaemia between healthy and severely ill patients. ${ }^{22}$ According to our results, HTC level is closely correlated with disease scores (namely APACHE II and SAPS II), which may indicate more severe underlying disease in patients with LHTC. This could explain why patients with LHTC appear to be more fragile and, therefore, are more likely to experience adverse events like MCE or death.

HTC is a component of diseases scoring systems, although its role as a risk factor for morbidity and mortality is incompletely understood. The knowledge of its importance will enable better management of current therapies available for HTC correction and help establish a trigger for transfusion, which still lacks consensus in the literature..$^{5,9}$

MCE were more common in LHTC patients, which was also noticed in previous studies. ${ }^{4,22}$ In a large sample of older non-cardiac surgical patients, Wu et a ${ }^{29}$ showed a higher cardiac morbidity rate with a preoperative HTC $<39 \%$. Another study ${ }^{22}$ also reported that high-risk patients with a postoperative HTC < 28\% more frequently had myocardial ischemia or other morbid cardiac events than those with a higher HTC.

Acute or chronic anaemia requires compensatory responses that place an extra burden on critically ill patients, many of whom have cardiopulmonary diseases. The main theory linking SICU anaemia and postoperative cardiac events is that the stress of surgery combined with increased metabolic demands may lead to cardiac ischemia and death. ${ }^{31}$ The impact of anaemia may be physiologically modulated by increased cardiac output, decreased peripheral vascular resistance, and decreased whole blood viscosity (to increase tissue perfusion), but it could be proarrhythmogenic or lead to a cardiac metabolic imbalance. ${ }^{32}$ As observed in our results, there was a parallel correlation between increasing HTC levels and decreasing both mortality and MCE rates. Wu and colleagues ${ }^{29}$ had also reported that the cardiac event rate increased monotonically for patients with progressively decreased HTC levels. On the other hand, the decreased blood viscosity could explain why patients with a higher HTC more often had a history of cerebrovascular disease. In fact, it was recently reported that an increase in HTC level is related to a decline in parenchymal cerebral blood flow. ${ }^{33}$

The limitations of this study are those intrinsic to retrospective cohort studies. Also, the preoperative risk assessment did not consider the evaluation of the patient's functional status, which remains noteworthy in the 2014 cardiovascular assessment European guidelines. ${ }^{34}$ However, some studies have reported no substantial association between functional status and MCE or death in the postoperative period. ${ }^{35}$ Patients' past medical histories were based on the RCRI, so important comorbidities that influence outcome could be missed. Nevertheless, RCRI remains a reliable cardiac risk index for non-cardiac surgery. In addition, some of the patients included in this study received transfusions, which may have influenced their outcomes.

\section{CONCLUSION}

In conclusion, an HTC level $<30 \%$ at SICU admission was frequent and appears to be a predictor for poorer outcome in critical surgical patients. We found that a lower HTC was correlated with a higher risk of ARF, MCE, or death during the SICU and hospital stay. HTC was strongly correlated with higher APACHE II and SAPS II scores.

\section{PROTECTION OF HUMANS AND ANIMALS}

The authors declare that the procedures were followed according to the regulations established by the Clinical Research and Ethics Committee and to the Helsinki Declaration of the World Medical Association.

\section{DATA CONFIDENTIALITY}

The authors declare having followed the protocols in use at their working center regarding patients' data publication.

\section{CONFLICTS OF INTEREST}

The authors report no conflict of interest.

\section{FUNDING SOURCES}

This research received no specific grant from any funding agency in the public, commercial, or not-for-profit sectors.

\section{REFERENCES}

1. Hartl WH, Wolf H, Schneider CP, Kuchenhoff H, Jauch KW. Acute and long-term survival in chronically critically ill surgical patients: a retrospective observational study. Crit Care. 2007;11:R55.

2. Astin R, Puthucheary Z. Anaemia secondary to critical illness: an unexplained phenomenon. Extrem Physiol Med. 2014;3:4.

3. Corwin HL, Gettinger A, Pearl RG, Fink MP, Levy MM, Abraham E, et al. The CRIT Study: Anemia and blood transfusion in the critically ill-current clinical practice in the United States. Crit Care Med. 2004;32:39-52.

4. Wang X, Qiu M, Qi J, Li J, Wang H, Li Y, et al. Impact of anemia on long-term ischemic events and bleeding events in patients undergoing percutaneous coronary intervention: a system review and meta-analysis. J Thorac Dis. 2015;7:2041-52.

5. Nichol AD. Restrictive red blood cell transfusion strategies in critical care: does one size really fit all? Crit Care Resusc. 2008;10:323-7. 
6. Musallam KM, Tamim HM, Richards T, Spahn DR, Rosendaal FR, Habbal $A$, et al. Preoperative anaemia and postoperative outcomes in noncardiac surgery: a retrospective cohort study. Lancet. 2011;378:1396407.

7. Pearse RM, Rhodes A, Moreno R, Pelosi P, Spies C, Vallet B, et al. EuSOS: European surgical outcomes study. Eur J Anaesthesiol. 2011;28:454-6.

8. Bernard AC, Davenport DL, Chang PK, Vaughan TB, Zwischenberger $\mathrm{JB}$. Intraoperative transfusion of $1 \mathrm{U}$ to $2 \mathrm{U}$ packed red blood cells is associated with increased 30-day mortality, surgical-site infection, pneumonia, and sepsis in general surgery patients. J Am Coll Surg. 2009;208:931-7.

9. Mudumbai SC, Cronkite R, Hu KU, Wagner T, Hayashi K, Ozanne GM, et al. Association of admission hematocrit with 6-month and 1-year mortality in intensive care unit patients. Transfusion. 2011;51:2148-59.

10. Carson JL, Brooks MM, Abbott JD, Chaitman B, Kelsey SF, Triulzi DJ, et al. Liberal versus restrictive transfusion thresholds for patients with symptomatic coronary artery disease. Am Heart J. 2013;165:964-71.

11. Chatterjee S, Wetterslev J, Sharma A, Lichstein E, Mukherjee D. Association of blood transfusion with increased mortality in myocardial infarction: a meta-analysis and diversity-adjusted study sequential analysis. JAMA Intern Med. 2013;173:132-9.

12. Naughton $\mathrm{C}$, Feneck RO. The impact of age on 6-month survival in patients with cardiovascular risk factors undergoing elective non-cardiac surgery. Int J Clin Pract. 2007;61:768-76.

13. Pontes SR, Salazar RM, Torres OJ. Perioperative assessment of the patients in intensive care unit. Rev Col Bras Cir. 2013;40:92-7.

14. Knaus WA, Draper EA, Wagner DP, Zimmerman JE. APACHE II: a severity of disease classification system. Crit Care Med. 1985;13:81829.

15. Le Gall JR, Lemeshow S, Saulnier F. A new simplified acute physiology score (SAPS II) based on a European/North American multicenter study. JAMA. 1993;270:2957-63.

16. McNelis J, Marini C, Kalimi R, Jurkiewicz A, Ritter G, Nathan I. A comparison of predictive outcomes of APACHE ॥ and SAPS II in a surgical intensive care unit. Am J Med Qual. 2001;16:161-5.

17. Lawrence VA, Hilsenbeck SG, Mulrow CD, Dhanda R, Sapp J, Page CP. Incidence and hospital stay for cardiac and pulmonary complications after abdominal surgery. J Gen Intern Med. 1995;10:671-8.

18. Lee TH, Marcantonio ER, Mangione CM, Thomas EJ, Polanczyk CA, Cook EF, et al. Derivation and prospective validation of a simple index for prediction of cardiac risk of major noncardiac surgery. Circulation 1999;100:1043-9.

19. Mangano DT, Layug EL, Wallace A, Tateo I. Effect of atenolol on mortality and cardiovascular morbidity after noncardiac surgery. Multicenter Study of Perioperative Ischemia Research Group. N Engl J Med. 1996;335:1713-20.

20. Wolfe Barry JA, Barth JH, Howell SJ. Cardiac troponins: their use and relevance in anaesthesia and critical care medicine. Continuing Education in Anaesthesia, Critical Care \& Pain. 2008;8:62-6.

21. Mangano DT, Hollenberg M, Fegert G, Meyer ML, London MJ, Tubau $\mathrm{JF}$, et al. Perioperative myocardial ischemia in patients undergoing noncardiac surgery--I: Incidence and severity during the 4 day perioperative period. The Study of Perioperative Ischemia (SPI) Research Group. J Am Coll Cardiol. 1991;17:843-50.

22. Nelson AH, Fleisher LA, Rosenbaum SH. Relationship between postoperative anemia and cardiac morbidity in high-risk vascular patients in the intensive care unit. Crit Care Med. 1993;21:860-6.

23. Myocardial infarction redefined--a consensus document of The Joint European Society of Cardiology/American College of Cardiology Committee for the redefinition of myocardial infarction. Eur Heart J. 2000;21:1502-13

24. van Iperen CE, Kraaijenhagen RJ, Biesma DH, Beguin Y, Marx JJ, van de Wiel A. Iron metabolism and erythropoiesis after surgery. Br J Surg. 1998;85:41-5.

25. Liumbruno GM, Bennardello F, Lattanzio A, Piccoli P, Rossetti G; Italian Society of Transfusion Medicine and Immunohaematology Working Party. Recommendations for the transfusion management of patients in the peri-operative period. III. The post-operative period. Blood Transfus. 2011;9:320-35.

26. Prakash D. Anemia in the ICU: anemia of chronic disease versus anemia of acute illness. Crit Care Clin. 2012;28:333-43.

27. Tohme S, Varley PR, Landsittel DP, Chidi AP, Tsung A. Preoperative anemia and postoperative outcomes after hepatectomy. HPB. 2016;18:255-61.

28. Ad N, Holmes SD, Massimiano PS, Spiegelstein D, Shuman DJ, Pritchard G, et al. Operative risk and preoperative hematocrit in bypass graft surgery: Role of gender and blood transfusion. Cardiovasc Revasc Med. 2015;16:397-400.

29. Wu WC, Schifftner TL, Henderson WG, Eaton CB, Poses RM, Uttley $\mathrm{G}$, et al. Preoperative hematocrit levels and postoperative outcomes in older patients undergoing noncardiac surgery. JAMA. 2007;297:2481-8.

30. Fowler AJ, Ahmad T, Phull MK, Allard S, Gillies MA, Pearse RM. Metaanalysis of the association between preoperative anaemia and mortality after surgery. Br J Surg. 2015;102:1314-24.

31. Hayden SJ, Albert TJ, Watkins TR, Swenson ER. Anemia in critica illness: insights into etiology, consequences, and management. Am J Respir Crit Care Med. 2012;185:1049-57.

32. Uscinska E, Idzkowska E, Sobkowicz B, Musial WJ, Tycinska AM. Anemia in intensive cardiac care unit patients - an underestimated problem. Adv Med Sci. 2015;60:307-14.

33. van der Veen PH, Muller M, Vincken KL, Westerink J, Mali WP, van der Graaf Y, et al. Hemoglobin, hematocrit, and changes in cerebral blood flow: the second manifestations of arterial disease-magnetic resonance study. Neurobiol Aging. 2015;36:1417-23.

34. Kristensen SD, Knuuti J, Saraste A, Anker S, Botker HE, De Hert S, et al. 2014 ESC/ESA Guidelines on non-cardiac surgery: cardiovascular assessment and management: The Joint Task Force on noncardiac surgery: cardiovascular assessment and management of the European Society of Cardiology (ESC) and the European Society of Anaesthesiology (ESA). Eur J Anaesthesiol. 2014;31:517-73.

35. Wiklund RA, Stein HD, Rosenbaum SH. Activities of daily living and cardiovascular complications following elective, noncardiac surgery. Yale J Biol Med. 2001;74:75-87. 